\title{
Aggregation States-Oxygen Permeability Relationships of Plasma-Polymerized Thin Films from Perfluorobenzene
}

\author{
Ichiro TERADA, Toshihide HARAGUCHI, ${ }^{*}$ and Tisato KAJIYAMA ${ }^{\dagger}$ \\ Department of Applied Chemistry, Faculty of Engineering, Kyushu University, \\ Hakozaki, Higashi-ku, Fukuoka 812, Japan \\ *Department of Chemical Engineering, Kitakyushu Technical College, \\ Kokura Minami-ku, Kitakyushu 803, Japan
}

(Received February 10, 1986)

\begin{abstract}
The plasma polymerization method was applied to prepare organic thin films from perfluorobenzene (PFB) which have good affinity to oxygen. The aggregation structures and permeation properties of plasma-polymerized thin films were investigated as functions of the magnitude of radiofrequency (RF) power, monomer flow rate, substrate temperature and annealing time after deposition. The chemical and aggregation structures of plasma-polymerized films were investigated on the basis of thermogravimetric measurement, infrared absorption spectra and X-ray photoelectron spectra. The unsaturated bond or aromatic ring changed into the highly crosslinked structure composed of saturated bonds with increases in the magnitude of RF power, substrate temperature and annealing time and also with decrease in the monomer flow rate. The magnitude of the separation factor through plasma-polymerized PFB (PPFB) films deposited on Millipore increased with an increase in the degree of crosslinking. In order to prepare the heat-resistant PPFB film, PFB was deposited on porous ceramics. The magnitude of oxygen permeability coefficient through the PPFB film deposited under the conditions of an RF power of $100 \mathrm{~W}$, a substrate temperature of $573 \mathrm{~K}$ and annealing time of $5 \mathrm{~h}$ remained almost constant at about $2.8 \times 10^{-8} \mathrm{~cm}^{3}$ (STP) $\mathrm{cm}^{-1} \mathrm{~s}^{-1} \mathrm{cmHg}^{-1}$ from 283 to $573 \mathrm{~K}$, and also, the separation factor gradually decreased from the magnitude of 4.5 at $283 \mathrm{~K}$ with an increase in temperature.

KEY WORDS Plasma Polymerization / Ultra-Thin Film / Aggregation

State / Perfluorobenzene / Fluorocarbon / Oxygen Enrichment Film /

Oxygen Permeation Property / Surface Structure / Crosslinking / Solubility

Coefficicent /
\end{abstract}

When evaluating permeation characteristics of penetrants through a film, the permeation rate is one of the important factors for practical use as well as the permeability coefficient and separation factor. As thinning of a film thickness is primarily required for an increase of the permeation rate, many methods to prepare an ultra-thin film have been developed. ${ }^{1-3}$

Preparation of a film by means of plasma polymerization have been intensively investigated, because almost all the organic subtances can be polymerized by this method. ${ }^{4}$
According to this method, it is possible to prepare a pinhole-free ultra-thin film a variety of substrates from various kinds of organic vapors. Moreover, it becomes possible to realize practical applications by choosing monomer substances which have high specific affinity for a certain kind of penetrant.

It is well-known that fluorocarbon monomers are used as artificial blood because of considerable affinity for oxygen gas. ${ }^{5}$ The authors previously reported that an introduction of fluorocarbon monomers into a polymer/liquid crystal composite film made

\footnotetext{
† To whom correspondence should be addressed.
} 
both the permeability coefficient of oxygen and the separation factor of oxygen to nitrogen increase. ${ }^{6-9}$ Though poly(tetrafluoroethylene) (PTFE) has good affinity for oxygen because of low surface energy, the permeation rate of oxygen is low due to its tight molecular packing and high degree of crystallinity, and also, it is difficult to prepare pinhole-free thin films of PTFE. Poly(tetrafluoroethylene-cohexafluoro-propylene) (FEP) ${ }^{10}$ and poly(perfluoro(2-methylene-4-methyl-1,3-dioxolane)) (PMD) ${ }^{11}$ which have bulky side chain groups were synthesized to obtain a high permeation rate. The permeability coefficient of oxygen through a PMD polymer film is $4 \times$ $10^{-9} \mathrm{~cm}^{3}(\mathrm{STP}) \mathrm{cm}^{-1} \mathrm{~s}^{-1} \mathrm{cmHg}^{-1}$ at $298 \mathrm{~K},{ }^{11}$ which is 10 times as large as PTFE. Since a plasma-polymerized film is completely amorphous, ${ }^{12,13}$ it is possible to prepare a film which has a considerable high permeability coefficient of oxygen.

In this study, plasma-polymerized thin films were prepared from fluorocarbon monomer and the relationships between aggregation structures and oxygen permeation properties were investigated.

\section{EXPERIMENTAL}

\section{Materials and Preparation of Plasma-Poly- merized Films}

Perfluorobenzene(PFB) was used as a fluorocarbon monomer in this study. The chemical structure is shown in Figure 1. Plasma-polymerized films were deposited on the substrates of Millipore VSWP (nominal pore size, $0.025 \mu \mathrm{m}$ ), Nucleopore (nominal pore size, $0.015 \mu \mathrm{m}$ ), porous ceramics (nominal pore size, $0.78 \mu \mathrm{m}$ ), aluminium foils, and precleaned glass plates. PFB was used as monomer since PFB was easy to introduce into the reaction vessel due to its high vapor pressure $^{14}$ and was easily polymerized at a higher deposition rate owing to its aromatic structure. $^{15}$

The bell-jar type reactor was used as

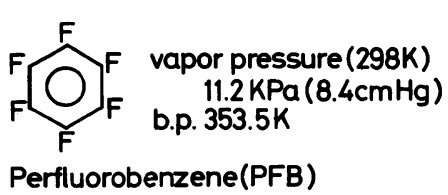

Figure 1. Chemical structure of perfluorobenzene ursed as a monomer.

a plasma polymerization reactor. Plasma was generated by a radio frequency (RF) of $13.56 \mathrm{MHz}$. Two parallel electrodes were set, the area of the upper electrode was 50.3 $\mathrm{cm}^{2}$, and the distance between the two electrodes was $3 \mathrm{~cm}$. Monomer was introduced between the electrodes from small nozzles of the upper electrode. The substrate was placed horizontally on the lower electrode whose temperature was controlled. Prior to plasma polymerization, argon plasma treatment (Ar $10 \mathrm{~Pa}$, Power $10 \mathrm{~W}$, plasma treatment for $1 \mathrm{~min}$ ) was carried out 3 times to remove air and water in the reactor. Plasma was previously generated by applying $13.56 \mathrm{MHz} \mathrm{RF}$ at a system pressure of $\mathrm{Ar} 10 \mathrm{~Pa}$, and subsequently deposition was started by the introduction of monomer into the reactor at a constant flow rate. The power input level to sustain the plasma condition, monomer flow rate, substrate temperature and annealing time at $573 \mathrm{~K}$ in vacuo were varied from 10 to $100 \mathrm{~W}, 0.9$ to $5.4 \mathrm{~cm}^{3}(\mathrm{STP}) \mathrm{min}^{-1}, 273$ to $573 \mathrm{~K}$, and 0 to $5 \mathrm{~h}$, respectively.

The polymer deposition rate was evaluated from a weight increase of the substrate, and the film thickness of a plasma-polymerized film was evaluated from the scanning electron microscopic (SEM) observation.

\section{Measurements}

Scanning Electron Microscopy (SEM): The surface states of plasma-polymerized films deposited on the glass plates at different magnitudes of power were observed using a Hitachi Scanning Electron Microscope (S430).

Infrared Spectroscopy (IR): In order to 
observe the structural change of plasmapolymerized films deposited at different power conditions, infrared spectra were obtained with the $\mathrm{KBr}$ tablet method, using a JASCO IR-2A.

Thermogravimetry $(T G)$ : Thermal properties of the deposited polymers were studied using a Shimazu Thermal Analyzer (Model DT-30).

$X$-ray Photoelectron Spectroscopy (XPS): X-Ray photoelectron spectra of deposited films were taken on a Shimadzu ESCA (Model S-750) employing a magnesium anode $\left(\mathrm{Mg} K_{\alpha}=1253.6 \mathrm{eV}\right)$, operating at $8 \mathrm{kV}$ and $30 \mathrm{~mA}$.

Gas Permeation Measurements: The permeability coefficients of oxygen and nitrogen through plasma-polymerized films were measured by a high vacuum method in the temperature range from 283 to $573 \mathrm{~K}$. An increase in pressure on the permeation side (down-stream side) was measured with a MKS Balatron gage as a function of time.

Sorption Measurements: Sorption measurements of oxygen and nitrogen to plasmapolymerized films were carried out using a Cahn 2000 electrobalance in the temperature range from 298 to $323 \mathrm{~K}$.

\section{RESULTS AND DISCUSSION}

\section{Characterization of Plasma-Polymerized Per-} fluorobenzene (PPFB) Film

In general, a plasma-polymerized film is heat-resistant ${ }^{12,16}$ because of the high degree of crosslinking. The permeation properties of gas molecules are strongly influenced by the degree of crosslinking, since crosslinking of molecules restricts the thermal molecular motion of plasma-polymerized polymer chains.

Figures 2(a) and (b) show the thermogravimetric (TG) curves of PPFB films deposited at (a) different radio-frequency (RF) powers, and (b) different monomer flow rates on glass plates kept at $273 \mathrm{~K}$. The temperature at the $95 \%$ weight residue of deposited polymer, $T_{\mathrm{D}}$, is evaluated as a measure of heat-stability. The
$T_{\mathrm{d}}$ increased with an increase in RF power, and also with a decrease in the monomer flow rate. An improvement of heatresistant character, in other words, an increase of $T_{D}$ corresponds to a reduction of thermal motions of plasma-polymerized molecules, which is attributed to the formation of crosslinking. These results indicate that the degree of crosslinking of PPFB films increases with an increase in the value of energy input level per unit mass flow, $W / F M$, where $W$ is RF power, $F$ is the monomer flow rate, and $M$ is the molecular weight of monomer. The effect of the substrate temperature on the heat-stability of a plasma-polymerized film was investigated for a PPFB film deposited under the condition of an RF power of $100 \mathrm{~W}$ and monomer flow rate of $5.4 \mathrm{~cm}^{3}(\mathrm{STP}) \mathrm{min}^{-1}$ as shown in Figure 2(c). The temperatures at the $95 \%$ weight residue for the PPFB films deposited at 273 , 373,473 , and $573 \mathrm{~K}$ were $578,593,617$, and $626 \mathrm{~K}$, respectively. Thus heat-stability increased with an increase in the substrate temperature. This fact is attributed to the removal of a low molecular weight component and/or proceeding of crosslinking on the substrate surface with an increase in the substrate temperatures. Figure 2(d) shows the annealing time dependence for the TG curves of PPFB films deposited on the glass plates at an RF power of $100 \mathrm{~W}$ and substrate temperature of $573 \mathrm{~K}$. Annealing treatment was carried out subsequently after plasma deposition at $573 \mathrm{~K}$ in vacuo. The $T_{\mathrm{D}}$ increased with an increase in annealing time. This shows that a low molecular weight component was removed and/or the degree of crosslinking increased with proceeding of the reaction induced by trapped radicals. Morinaka and Asano reported that the concentration of trapped radicals in plasma-polymerized films from hexamethyldisiloxane decreased in the order of annealing temperatures of 423,373 , and $323 \mathrm{~K}^{17}$

Figure 3 exhibits the SEM photographs for the fracture and the film surfaces of PPFB films deposited at different powers on the glass 


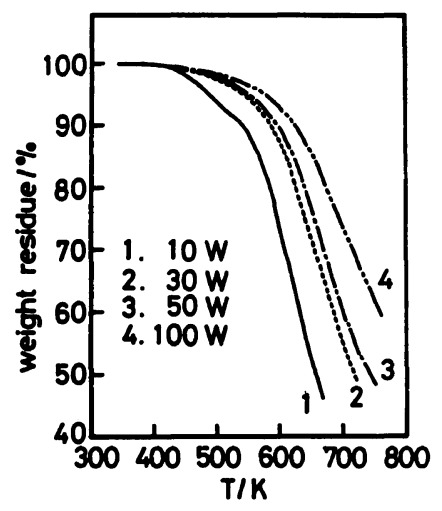

(a)

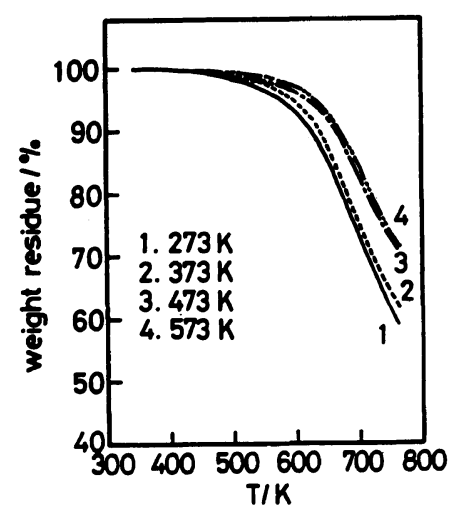

(c)

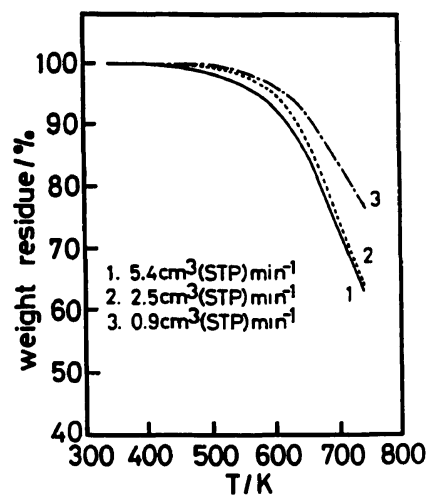

(b)

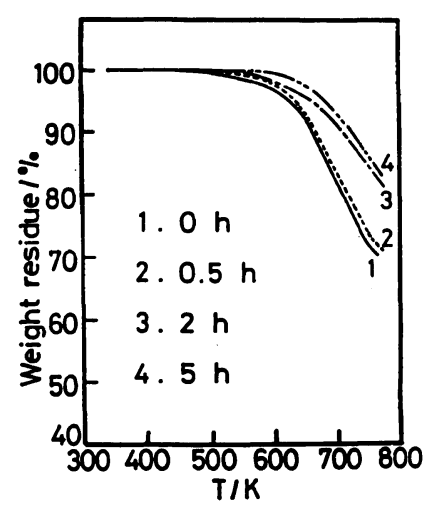

(d)

Figure 2. TG curves for the plasma-polymerized films deposited on glass plate as functions of RF power (a) $(1,10 \mathrm{~W} ; 2,30 \mathrm{~W} ; 3,50 \mathrm{~W} ; 4,100 \mathrm{~W})$, monomer flow rate (b) $\left(1,5.4 \mathrm{~cm}^{3}(\mathrm{STP}) \mathrm{min}^{-1} ; 2\right.$, $\left.2.5 \mathrm{~cm}^{3}(\mathrm{STP}) \mathrm{min}^{-1} ; 3,0.9 \mathrm{~cm}^{3}(\mathrm{STP}) \mathrm{min}^{-1}\right)$, substrate temperature (c) $(1,273 \mathrm{~K} ; 2,373 \mathrm{~K} ; 3,473 \mathrm{~K} ; 4$, $573 \mathrm{~K})$ and annealing time at $573 \mathrm{~K}(\mathrm{~d})(1,0 \mathrm{~h} ; 2,0.5 \mathrm{~h} ; 3,2 \mathrm{~h} ; 4,5 \mathrm{~h})$.

plates at $273 \mathrm{~K}$. In the case of an RF power of $10 \mathrm{~W}$, the surface of a PPFB film was rough and coarse. On the other hand, in the case of $P=30,50$, and $100 \mathrm{~W}$, the surface became smooth and uniform, being the characteristic of a dense film. Since, in the case of low RF power, a decrease in the system pressure due to polymerization is small due to the low electron energy, the plasma is generated only between the electrodes serial PFB introduced through many nozzles of the upper electrode deposites rapidly on the substrate placed on the lower electrode. Moreover, since ablation is slight, the PPFB film surface became rough and coarse as shown in Figure 3(a). When the RF power is high, the electron energy of plasma is high and the mean free path of activated species is large because of a decrease in pressure. Therefore, plasma expands entirely in the bell-jar, and PFB is deposited slowly onto the substrate surface, with both polymerization and ablation proceeding. Thus, fairly uniform surfaces are obtained as shown in Figure 3(b), (c), and (d). However, in the case of an RF power of $100 \mathrm{~W}$, the effect of ablation is remarkable, resulting in removal of the low molecular component during polymerization. This plasma polymerization forms the slightly 


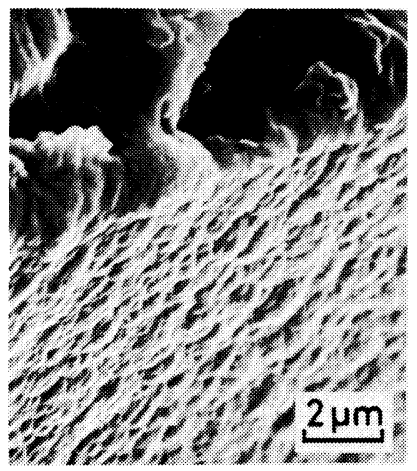

(a) $10 \mathrm{~W}$

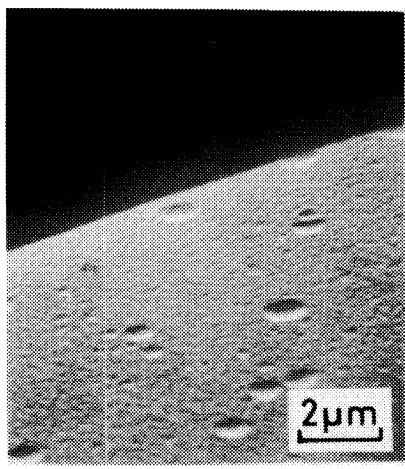

(c) $50 \mathrm{~W}$

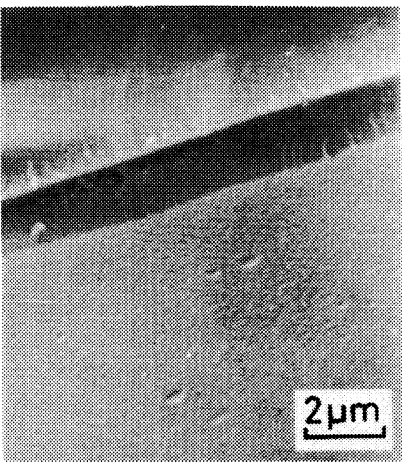

(b) $30 \mathrm{~W}$

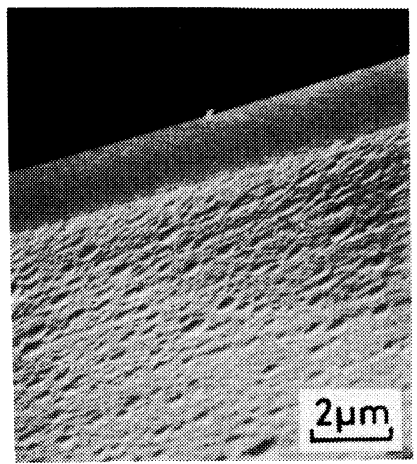

(d) $100 \mathrm{~W}$

Figure 3. SEM photographs for the fracture and film surfaces of plasma-polymerized perfluorobenzene films deposited on glass plates at different RF powers (a), $10 \mathrm{~W}$; (b), $30 \mathrm{~W}$; (c), $50 \mathrm{~W}$; (d), $100 \mathrm{~W}$.

rough surface. Plasma polymerization at the $\mathrm{RF}$ power of $100 \mathrm{~W}$ and the other substrate temperatures give a similar surface morphology to that of the PPFB film deposited at an RF power of $100 \mathrm{~W}$ and the substrate temperature of $273 \mathrm{~K}$. This indicates that surface morphology is primarily influenced by the magnitude of RF power.

The degree of crosslinking was investigated by IR measurements. Figure 4(a) shows the IR spectra of PFB monomer and PFB polymer (PPFB) deposited at an RF power of $30 \mathrm{~W}$ and substrate temperature of $273 \mathrm{~K}$. PFB exhibits three characteristic sharp absorptions at 1530 , 1020 , and $995 \mathrm{~cm}^{-1}$ which were assigned to the C-F stretching, deformation of a benzene-type ring and the same type of deformation, respectively. ${ }^{18}$ In the case of PPFB films, these absorption peaks became broad and less pronounced, indicating the formation of crosslinking in the deposited polymer. Though, even in the case of a PPFB film, the two weak absorption bands were still observed at 1500 and $995 \mathrm{~cm}^{-1}$, reflecting the existence of monomer structure, the strong absorption assigned to the $-\mathrm{CF}_{2}-$ and $-\mathrm{CF}_{3}$ stretching mode in the polymeric chain were observed at $1200 \mathrm{~cm}^{-1}$ which indicates opening of a benzene type ring. In order to evaluate the fraction of PFB monomer decomposed by plasma radiation, the ratio of the absorbance at $1200 \mathrm{~cm}^{-1}, A_{1200 \mathrm{~cm}^{-1}}$, to the 


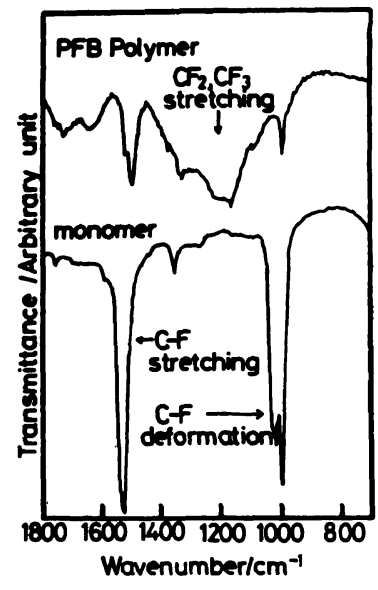

(a)

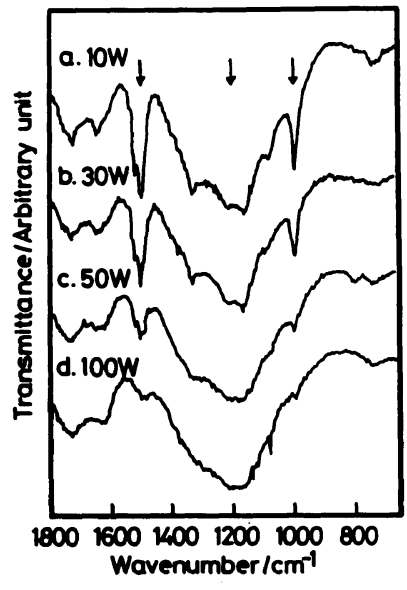

(b)

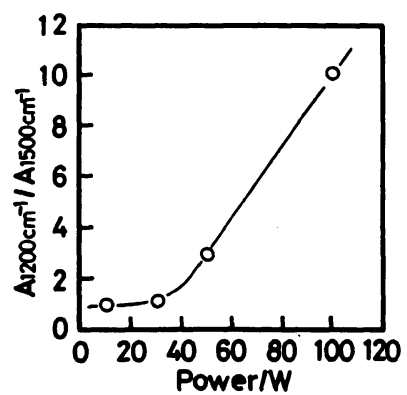

(c)

Figure 4. IR spectra of perfluorobenzene monomer and the polymers (a) (a, plasma-polymerized perfluorobenzene; $b$, perfluorobenzene monomer), plasma-polymerized perfluorobenzene deposited at different powers (b) (a, $10 \mathrm{~W} ; \mathrm{b}, 30 \mathrm{~W} ; \mathrm{c}, 50 \mathrm{~W} ; \mathrm{d}, 100 \mathrm{~W})$ and power dependence of the ratio of absorbance. at $1200 \mathrm{~cm}^{-1}$ to one at $1500 \mathrm{~cm}^{-1}, A_{1200 \mathrm{~cm}^{-1}} / A_{1500 \mathrm{~cm}^{-1}}$ (c).

one at $1500 \mathrm{~cm}^{-1}, A_{1500 \mathrm{~cm}^{-1}}$, was calculated, since the absorption of $1200 \mathrm{~cm}^{-1}$ reflects polymer structure and that at $1500 \mathrm{~cm}^{-1}$, monomer structure. The ratio, $A_{1200 \mathrm{~cm}^{-1}} /$ $A_{1500 \mathrm{~cm}^{-1}}$ increased with an increase in RF power as shown in Figure 4(c). This indicates that plasma polymerization of PFB proceeds remarkably above an RF power of $40 \mathrm{~W}$.

\section{Chemical Surface State of PPFB Films}

It is important to investigate the chemical surface state which influences sorption of gas to the film surface. The chemical surface state was studied on the basis of XPS measurements. The results of wide scan revealed that a PPFB film consisted of $\mathrm{C}, \mathrm{F}, \mathrm{O}$, and $\mathrm{H}$ atoms. Figure 5 shows the $C_{1 s}$ spectra for PPFB films deposited on Al foils at the different (a) magnitudes of RF power, (b) monomer flow rate, (c) substrate temperature and (d) annealing time. Six peaks or shoulders were observed in each spectra. The shoulder at the lowest binding energy is assigned to the hydrocarbon type carbon (- $-\mathrm{CH}-)$ and is used as a reference at $285.0 \mathrm{eV}$. The peak at $287.1 \mathrm{eV}$ is assigned to the carbon adjacent to that bonded to fluorine atoms $(-\underline{C}-\mathrm{CF})$ or singly bonded to oxygen $(-\mathrm{C}-\mathrm{O}-) .{ }^{19}$ The spectra for the carbon bonded to fluorine atoms were observed at a region of higher binding energy. The shoulder at $288.5 \mathrm{eV}$ and the peak at $289.2 \mathrm{eV}$ were assigned to the $-\mathrm{CF}-\mathrm{CF}-$ or $-\underline{\mathrm{C}}=\mathrm{O}$ type carbon ${ }^{19}$ and $-\underline{C} F-C^{-} F_{n}(n=$ 2 or 3$),-C F-C F-C F-$ or perfluorobenzene type carbon, respectively. Moreover, the peak at $291.5 \mathrm{eV}$ and shoulder at $293.9 \mathrm{eV}$ arise from $-\underline{C F}_{2}-$ and $-\underline{C F}_{3}$ type carbon, respectively. Figure 5(a) shows that the relative peak height at about $289.2 \mathrm{eV}$ (- $\underline{\mathrm{CF}}-)$ decreases and the peaks at 287.1 ( $-\mathrm{C}-\mathrm{CF}-)$ and $291.5 \mathrm{eV}\left(-\mathrm{CF}_{2}-\right)$ became more remarkable with increasing RF power. Figure 5(b) shows the PFB flow rate dependence of the $\mathrm{C}_{1 \mathrm{~S}}$ spectra of PPFB films deposited under the condition of an RF power of $100 \mathrm{~W}$ and substrate temperature of $273 \mathrm{~K}$. The $-\underline{C F}-$ group is attributed to monomer or similar unsaturated structure and the $-\underline{C}-\mathrm{CF}-$ group to crosslinking structure. The relative decrease of the fraction of $-\underline{C F}$ - structure to that of $-\mathrm{C}-\mathrm{CF}$ - structure indicates that the monomer type structure or $-\underline{C} F-$ type structure con- 


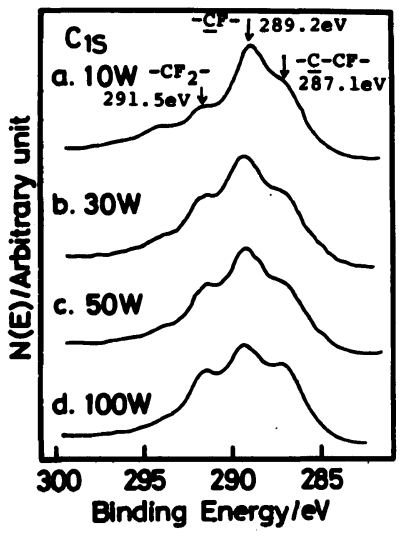

(a)

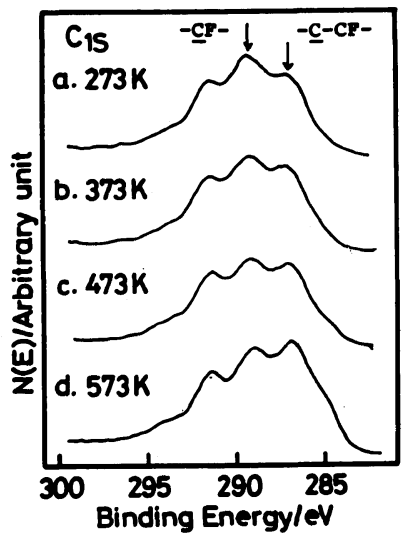

(d)

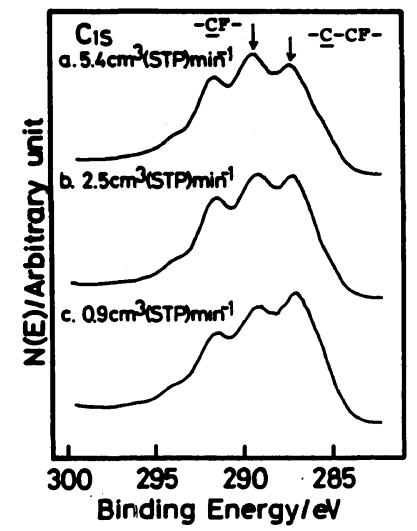

(b)

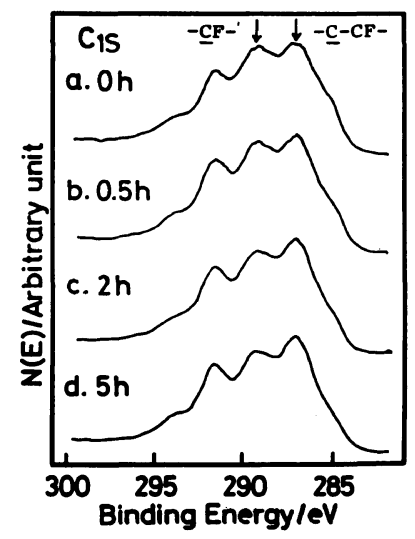

(e)

Figure 5. Carbon 1S spectra of plasma-polymerized perfluorobenzene deposited on $\mathrm{Al}$ foils as a function of radio-frequency power (a) (a, $10 \mathrm{~W} ; \mathrm{b}, 30 \mathrm{~W} ; \mathrm{c}, 50 \mathrm{~W} ; \mathrm{d}, 100 \mathrm{~W})$, the monomer flow rate (b) (a, $5.4 \mathrm{~cm}^{3}$ (STP) $\mathrm{min}^{-1} ; \mathrm{b}, 2.5 \mathrm{~cm}^{3}$ (STP) $\mathrm{min}^{-1} ; \mathrm{c}, 0.9 \mathrm{~cm}^{3}$ (STP) $\mathrm{min}^{-1}$ ), the substrate temperature (c) (a, $273 \mathrm{~K}$; b, $373 \mathrm{~K}$; c, $473 \mathrm{~K} ; \mathrm{d}, 573 \mathrm{~K})$ and the annealing time (d) (a, $0 \mathrm{~h} ; \mathrm{b}, 0.5 \mathrm{~h} ; \mathrm{c}, 2 \mathrm{~h} ; \mathrm{d}, 5 \mathrm{~h})$.

taining double bond were decomposed with an increase in energy input level per unit mass, $W / F M$, and polymerization state was approached to the atomic one. Figure 5(c) shows the substrate temperature dependence of the $\mathrm{C}_{1 \mathrm{~s}}$ spectra of PPFB deposited at an RF power of $100 \mathrm{~W}$ and monomer flow rate of $5.4 \mathrm{~cm}^{3}(\mathrm{STP}) \mathrm{min}^{-1}$. When the substrate temperature was increased, similar behavior to the case of RF power dependence was observed, indicating an increase in the degree of crosslinking with an increase in the substrate temperature. The annealing time at $573 \mathrm{~K}$ in vacuo does not exhibit a remarkable change in the fraction of $-\mathrm{C}-\mathrm{CF}$ - structure as shown in Figure 5(d).

\section{Gas Permeation through Plasma-Polymerized Films}

Figure 6 shows the film thickness dependence of the apparent permeation rate of oxygen gas, $R_{\mathrm{O}_{2}}$, and the permeation rate ratio, $\alpha\left(=R_{\mathrm{O}_{2}} / R_{\mathrm{N}_{2}}\right)$, at $298 \mathrm{~K}$ through the PPFB films deposited on Millipore at RF powers of 10,30 and $50 \mathrm{~W}$ and a substrate temperature of $273 \mathrm{~K}$. In the case of $10 \mathrm{~W}$, 


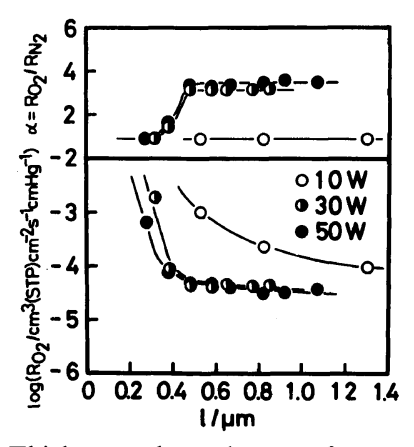

Figure 6. Thickness dependence of apparent permeation rate of oxygen, $R_{\mathrm{O}_{2}}$, and separation factor, $\alpha$, for plasma-polymerized perfluorobenzene films deposited on Millipore under the conditions of a monomer flow rate of $5.4 \mathrm{~cm}^{3}$ (STP) $\mathrm{min}^{-1}$ and substrate temperature of $273 \mathrm{~K}$ as a function of RF power.

though $R_{\mathrm{O}_{2}}$ decreased with an increase of the film thickness, $\alpha$ remains constant at about $0.9-1.0$ within the thickness range studied here, indicating no permselectivity. On the other hand, in the cases of 30 and $50 \mathrm{~W}$, the magnitude of $\alpha$ increased and simultaneously, the permeation rate decreased drastically in the vicinity of the film thickness of 0.2 $0.4 \mu \mathrm{m}$. Though the nominal pore size of the substrate membrane (Millipore) is $0.025 \mu \mathrm{m}$, the largest one is about $0.15-0.2 \mu \mathrm{m}$ on the basis of SEM observation. These results indicate that the pores were covered with a plasma-polymerized film and pinhole-free thin films were formed in the case of the film thickness of around $0.3 \mu \mathrm{m}$. When Nucleopore with a uniform pore size of $0.015 \mu \mathrm{m}$ was used as a substrate, pinhole-free films were obtained in the case of the film thickness of 0.03 $0.05 \mu \mathrm{m}$. This indicates that it is necessary to deposit a PPFB film more than about 2 times as thick as the largest pore diameter of the substrate membrane in order to prepare pinhole-free plasma-polymerized films. In a thickness range above $0.4 \mu \mathrm{m}$, the apparent permeation rate of oxygen was about $10^{-4}$ $10^{-5} \mathrm{~cm}^{3}$ (STP) $\mathrm{cm}^{-2} \mathrm{~s}^{-1} \mathrm{cmHg}^{-1}$ and the permeation rate ratio, was almost constant at 3.2 and 3.5 for RF powers of 30 and $50 \mathrm{~W}$, respectively. Since the magnitude of $\alpha$ was

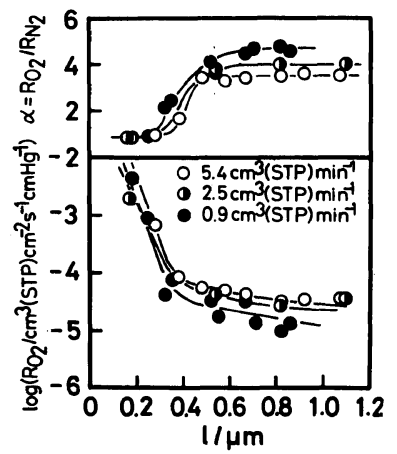

Figure 7. Thickness dependence of apparent permeation rate of oxygen, $R_{\mathrm{O}_{2}}$, and separation factor, $\alpha$, for plasma-polymerized perfluorobenzene films deposited on Millipore under the conditions of an RF power of $50 \mathrm{~W}$ and substrate temperature of $273 \mathrm{~K}$ as a function of monomer flow rate.

highest in the case of the RF power of $50 \mathrm{~W}$, permeation properties were investigated as a function of the monomer flow rate at an RF power of $50 \mathrm{~W}$. Figure 7 shows the thickness dependence of the $R_{\mathrm{O}_{2}}$ and $\alpha$ at $298 \mathrm{~K}$ through the PPFB films deposited on Millipore at an RF power of $50 \mathrm{~W}$ and substrate temperature of $273 \mathrm{~K}$ as a function of the monomer flow rate. The magnitude of $R_{\mathrm{O}_{2}}$ decreased and also $\alpha$ increased with a decrease in the monomer flow rate in a thickness range above $0.4 \mu \mathrm{m}$. These results correspond to the fact that the degree of crosslinking increases due to an increase in the evergy input level in the case of the smaller monomer flow rate. In the case of $F=0.9 \mathrm{~cm}^{3}(\mathrm{STP}) \mathrm{min}^{-1}, \alpha$ was $4.5-4.8$ above $0.6 \mu \mathrm{m}$ in thickness and $R_{\mathrm{O}_{2}}$ was about $1 \times$ $10^{-5} \mathrm{~cm}^{3}(\mathrm{STP}) \mathrm{cm}^{-2} \mathrm{~s}^{-1} \mathrm{cmHg}^{-1}$. Since the pinhole-free films were formed in the region of the film thickness of around $0.3 \mu \mathrm{m}$ from Figures 6 and 7, this thickness was subtracted from those estimated by SEM observation, and the permeability coefficient of oxygen, $P_{\mathrm{O}_{2}}$ was calculated using this corrected thickness and the porosity of Millipore. The porosity of Millipore pretreated with Ar plasma was about $30-40 \%$ on the basis of SEM observations, $P_{\mathrm{O}_{2}}$ was estimated to be about $1.7 \times$ $10^{-9} \mathrm{~cm}^{3}(\mathrm{STP}) \mathrm{cm}^{-1} \mathrm{~s}^{-1} \mathrm{cmHg}^{-1}$. 


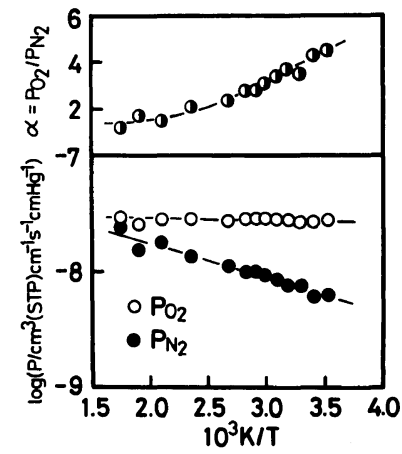

Figure 8. Arrhenius plots of permeability coefficient, $P_{\mathrm{O}_{2}}, P_{\mathrm{N}_{2}}$ and separation factor, $\alpha$, of $\mathrm{O}_{2}$ and $\mathrm{N}_{2}$ gases for the plasma-polymerized perfluorobenzene films deposited on porous ceramics under the conditions of an RF power of $100 \mathrm{~W}$, monomer flow rate of $5.4 \mathrm{~cm}^{3}$ (STP) $\mathrm{min}^{-1}$, substrate temperature of $573 \mathrm{~K}$ and annealing time of $5 \mathrm{~h}$.

In order to prepare a heat-resistant gas separation membrane, porous ceramics were used as the heat-resistant substrate. Since the nominal pore size of the porous ceramics was 30 times as large as that of Millipore, plasma deposition was carried out for $7 \mathrm{~h}$ under at an RF power of $100 \mathrm{~W}$, substrate temperature of $573 \mathrm{~K}$ and monomer flow rate of $5.4 \mathrm{~cm}^{3}(\mathrm{STP}) \mathrm{min}^{-1}$, to prepare pinhole-free films. The PPFB film thus prepared was annealed for $5 \mathrm{~h}$ at $573 \mathrm{~K}$ in vacuo. Figure 8 shows the Arrhenius plots of the permeability coefficient for oxygen and nitrogen, $P_{\mathrm{O}_{2}}$ and $P_{\mathrm{N}_{2}}$ through a PPFB film deposited on the porous ceramics. Though the permeability coefficient of oxygen at $293 \mathrm{~K}$ through a PPFB film before annealing was about $7 \times 10^{-9} \mathrm{~cm}^{3}(\mathrm{STP}) \mathrm{cm}^{-1} \mathrm{~s}^{-1} \mathrm{cmHg}^{-1}$, that after annealing treatment increased 3 times to about $2 \times 10^{-8} \mathrm{~cm}^{3}(\mathrm{STP}) \mathrm{cm}^{-1} \mathrm{~s}^{-1}$ $\mathrm{cmHg}^{-1}$. This indicates that the permeating channel increases by removal of low molecular components. As shown in Figure 8, the permeability coefficient of oxygen, $P_{\mathrm{O}_{2}}$ remained almost constant in the temperature range studied here, and also, $\alpha$ gradually decreased from the magnitude of 4.5 at $283 \mathrm{~K}$ with an increase in temperature. At the present time,
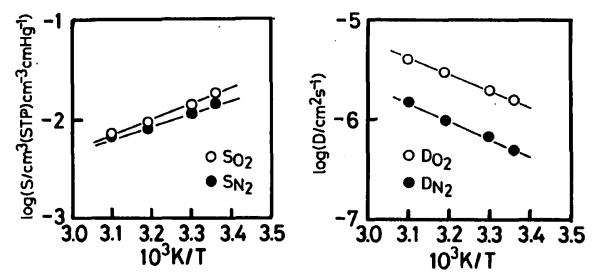

Figure 9. Arrhenius plots of solubility coefficient (a) and diffusion coefficient (b) for $\mathrm{O}_{2}$ and $\mathrm{N}_{2}$ gases for the PPFB film deposited under the conditions of an RF power of $100 \mathrm{~W}$, substrate temperature of $573 \mathrm{~K}$ and annealing time of $5 \mathrm{~h}$.

we have not measured $P_{\mathrm{O}_{2}}$ at a higher temperature (about $600 \mathrm{~K}$ ) because we could not find any elastic packing to seal the permeation cell.

Figure 9 shows the temperature dependences of the solubility coefficient, $S$ of oxygen and nitrogen (a), and of the diffusion coefficient, $D$ (b) for a PPFB film. The magnitude of $D$ was evaluated from that of $P$ and $S$ using the equation of $P=D S$. Though the difference between the solubility coefficients of oxygen and nitrogen is not large, the magnitudes of these solubility coefficients are larger than those for poly(dimethylsiloxane) and poly(tetrafluoroethylene-co-hexafluoropropylene), indicating higher solubility of $\mathrm{O}_{2}$ and $\mathrm{N}_{2}$ to plasma-polymerized fluorocarbon polymer. On the other hand, the difference between the diffusion coefficients of $\mathrm{O}_{2}$ and $\mathrm{N}_{2}$ is large and it is apparent that separation through a PPFB film is based on diffusion.

In conclusion, the degree of crosslinking of a PPFB film increased with RF power, substrate temperature, annealing time after deposition and decrease in the monomer flow rate. The oxygen permeation rate through a PPFB film decreased and the permeation rate ratio of oxygen to nitrogen increased with an increase in the degree of crosslinking. The apparent permeability coefficient of oxygen through a PPFB film deposited on the porous ceramics increased remarkably upon annealing treatment at $573 \mathrm{~K}$ because of an increase in the free volume by removal of low molecular 
components. The excellent permeation behavior of oxygen and nitrogen through a PPFB film was attributed to the high solubilities of those gases at the PPFB surface and also, differences in diffusion properties between them.

\section{REFERENCES}

1. W. J. Ward, W. R. Browall, and R. M. Salemme, J. Membrane Sci., 1, 99 (1976).

2. S. Manjikian, Ind. Eng. Chem. Prod. Res. Dev., 6, 23 (1967).

3. A. F. Stancell and A. T. Spencer, J. Appl. Polym. Sci., 16, 1505 (1972).

4. M. Shen and A. T. Bell, "Plasma polymerization," ACS Symposium Ser. 108, 1972, p 2.

5. E. P. Wesseler, R. Iltis, and L. C. Clark, Jr., J. Fluorine Chem., 9, 137 (1977).

6. T. Kajiyama, S. Washizu, and Y. Ohmori, $J$. Membrane Sci., 24, 73 (1985).

7. T. Kajiyama, S. Washizu, A. Kumano, I. Terada, M. Takayanagi, and S. Shinkai, Appl. Polym. Symp., 41, 327 (1985).
8. Y. Ohmori and T. Kajiyama, Nippon Kagaku Kaishi, .1897 (1985).

9. T. Kajiyama, H. Kikuchi, I. Terada, M. Katayose, A. Takahara, and S. Shinkai, Current Topics in Polym. Sci., in press.

10. R. A. Pasternak, G. L. Burns, and J. Heller, Macromolecules, 4, 470 (1971).

11. E. L. Niedzielski and R. E. Putnam, US Patent 3,303,330.

12. H. Kobayashi, A. T. Bell, and M. Shen, J. Appl. Polym. Sci., 17, 885 (1973).

13. L. F. Thompson and K. G. Mayhan, J. Appl. Polym. Sci., 16, 2317 (1972).

14. C. R. Patrick and G. S. Prosser, Trans. Faraday Soc., 60, 700 (1964).

15. H. Yasuda, J. Polym. Sci., Macromol. Rev., 16, 199 (1981).

16. J. P. Whiteman and N. J. Johnston, Adv. Chem. Ser., 80, 322 (1969).

17. A. Morinaka and Y. Asano, J. Appl. Polym. Sci., 27, 2139 (1982).

18. D. Steele and D. H. Whiffen, Trans. Faraday Soc., 55, 369 (1959).

19. D. T. Clark and D. Shuttleworth, J. Polym. Sci., Polym. Chem. Ed., 18, 27 (1980). 